\title{
Potential Opportunities in the Development of China's Belt and Road Initiative in Terms of Policies of the US to the Islamic World
}

\author{
Shijie Zhou \\ Central China Normal University,Wuhan,Hubei,China \\ 710320317@qq.com
}

Keywords: American diplomacy, Islamic World, Belt and Road

\begin{abstract}
Since the 1979 Islamic revolution, the American attitude toward Iran's Shiite political Islam is trying to kill, exaggerate the so-called "Islamic threat" constantly, and caused the Islamic world general anti-western miscalculation. Meanwhile, the Sunni political Islam of Afghanistan is being cultivated to defend against the Soviet Union and Iran. But it is also a recipe for Islamic extremism. After the September 11 attacks, the United States began to rethink its policy toward the Islamic world, revisiting its own diplomatic relations with the Islamic world through a lens of interest rather than clash of civilizations. The "One Belt And One Road" strategy is an important step in China's "going out" and will carry out cooperation and exchanges with many Islamic countries along the line. America's attitude to the Islamic world and policy shift will bring China's "neighborhoods" all the way many possible opportunity, for example in the field of trade expansion, and the ease of religious conflict as well as the improvement of public opinion, etc., is good for China.
\end{abstract}

\author{
从美国对伊斯兰世界的政策 \\ 探讨中国“一带一路”发展的可能契机 \\ 周诗婕 \\ 华中师范大学马克思主义学院, 武汉, 湖北, 中国 \\ 710320317@qq.com
}

关键词：美国外交; 伊斯兰世界; 一带一路

中文摘要. 从1979年伊朗革命以来, 美国对伊朗什叶派政治伊斯兰的态度一直是以竭力扼杀 为主，不断夸大所谓的“伊斯兰威胁”，并造成了伊斯兰世界总体反西方的一些误判。同时扶 植阿富汗的逊尼派政治伊斯兰, 借此抵抗苏联和伊朗。但是这也为伊斯兰极端主义的生长埋 下了祸根。“9.11”事件之后，美国开始重新思考对伊斯兰世界的政策，重新以利益导向而不 是文明冲突的视角来审视自身与伊斯兰世界的外交。“一带一路”战略是我国“走出去”的重要 一步，沿线将于众多伊斯兰国家开展合作与交流。美国对伊斯兰世界的态度和政策的转变将 为中国的“一带一路”带来许多的可能契机, 例如贸易领域的拓展、宗教矛盾的缓和以及民众 观念的改善等等, 对中国无疑是有利的。 


\section{1. 引言}

本文将致力于梳理美国对以政治伊斯兰为主的伊斯兰世界政策的变化，分析其历史发展 趋势和现今发展状态, 并对其变化可能对中国 “一带一路” 战略实施所带来的影响进行预估, 挖掘其中的现实意义和对我国的影响。

\section{2. 美国对伊斯兰世界政策的变迁: 从全盘打压到理性对待}

美国对政治伊斯兰的认知和政策，可以人为地分为三个阶段—-1979年伊朗的伊斯兰革 命之前、1979年到“9.11”事件发生、“9.11”事件之后。

1979年之前, 美国对政治伊斯兰的关注仅限于影响较大的逊尼派伊斯兰组织。而1979年 伊朗的伊斯兰革命以后, 什叶派政治伊斯兰逐步以暴动、起义等非和平的手段登上了历史舞 台。与此同时, 冷战之后, 美国获得了世界上唯一的 “超级大国” 地位, 由于种种原因, 对 什叶派政治伊斯兰的政策一直处于 “竭力遏制”、“不留余地” 的状态。其中，国际政治权 利的分配不均衡是根本原因, 另外还夹杂着战略因素、经济因素、资源因素等各方面的伴生 原因，交织在一起。

对于对整个政治伊斯兰政策, 西方学界一直存在两个观点, 即对抗派和融合派。对抗派 学者认为, 政治伊斯兰是西方的敌人, 他是宗教伊斯兰的派生物, 沿袭甚至发展了宗教伊斯 兰的原教旨主义，继承了其中的反人类的特质，他们甚至是全人类的敌人。丹尼尔 - 派普斯 认为, “伊斯兰原教旨主义是一个乌托邦式的激进运动, 与传统宗教相比, 它与共产主义、 纳粹主义等运动在精神上相近”。该派学者还从战略高度评估 “伊斯兰威胁” ，将其与前苏 联相提并论, 认为政治伊斯兰是冷战后美国的 “新敌人”。融合派的观点则相对温和, 但是 从里根到小布什政府, 似乎都更倾向于采取对抗派的观点, 大有 “宁可错杀三千, 不可放过 一个”的意味。

而在 “9.11”事件之后, 美国开始认识到这样的外交形式, 非但没有遏制什叶派政治伊 斯兰的膨胀, 反而造成了原教旨主义的发展和极端主义的壮大, 对美国乃至世界的安全笼罩 上了恐怖的阴影。因此美国开始一面采取各种反恐行动, 打击伊斯兰激进主义, 一面加紧与 温和派接触, 推动巴以和谈、实施撤军等行为, 体现了美国正在考虑不再以文明的冲突而开 始以利益为导向来评价与伊斯兰世界的关系。他们不再一味地打压或纵容某一派, 而是以恐 怖主义为终极敌对目标。

\section{3. 中国在 “一带一路” 建设上与伊斯兰世界的合作与摩擦}

\section{1 历史上的合作: 经济往来与文化交融}

早在公元7世纪左右, 中国人用 “大食” 来称呼阿拉伯帝国, 用 “天方” 来称呼伊斯兰教 发源地麦加, 后泛指阿拉伯一伊斯兰世界。经济上, 唐代时得益于丝绸之路, 中国与伊斯兰 世界的贸易繁荣异常。曾有 “海舶连大食, 丝路通天方”之说。中国的丝绸、瓷器通过中东进 入欧洲, 受到西方上流社会的追捧; 伊斯兰世界的物种流入我国, 双边贸易有序开展。政治 上, 自唐代开始, 大食就是中国在中东最为强大的盟友, 唐德宗贞元三年(787年), 宰相李泌曾 一度主张联合大食以制衡吐蕃: “大食在西域为最强,自憼岭尽西海,地几半天下,代与吐蕃为仇, 故知其可结。”（邹否，2013）同时, 在文化传承方面, 从中国古代文献中记载的一批带有 “胡” 字的植物, 如胡桃、胡瓜、胡椒、胡罗卜等中可以看出,这些物种也大多是在这一时期由 伊斯兰世界传入中国。各种珍禽异兽、香药珠宝、金银货币、音乐、舞蹈、饮食、服饰等大 量传入中国。可以说,正是由于这一时期的交往, 华夏文明同伊斯兰文明相互交融、相互影响, 为多元文化的形成奠定了良好的基础, 也为世界文明进步做出了贡献。综上所诉, 中国同伊 斯兰世界的接触与合作有着十分悠久的历史。 
同时，自我国开始实施 “一带一路” 战略以来，我国和伊斯兰国家不仅在能源资源购买、 基础设施建设、文化教育输出等各方面加大了合作的力度, 而且间接地带去了技术、就业机 会、以及文化交流的契机等等，这些都广泛的促进了中伊双方的友好合作。

\section{2 现实中的摩擦: 宗教信仰与贸易垄断}

有合作就不可避免会产生摩擦。一方面, 由于某些极端恐怖主义对于全世界和平稳定秩 序的破坏, 对中国同伊斯兰世界的正常经贸往来和文化交流造成了极大的影响, 尤其是我国 实行 “向西开放” 战略和 “一带一路” 战略以来, 虽然中缅、中俄油气管道的确在某种程度 上减轻了马六甲海峡和波斯湾的油气运输压力, 也是中方免受了许多损失。但是中国仍然是 中东举足轻重的资源顾客, 近半数的油气资源都来自中东伊斯兰世界。如果极端势力从中作 梗，将不可避免地造成巨大的经济损失和人员伤亡。

另一方面，我国本身是一个宗教信仰自由的国家，相当大一部分民众没有宗教信仰，但 是由于宗教极端主义和恐怖主义份子或少数打着伊斯兰教旗号的政治组织、个人和团体,为了 实现其政治目的, 故意曲解和颠覆伊斯兰文化和思想, 并以此为指导和支撑, 来实施暴力恐怖活 动。使得部分民众对伊斯兰教、穆斯林一味地敌视, 这对我国国内民族团结和社会安定形成 阻碍，也让我国人才赴外交流、资金向外流动、文化相互交融都产生了巨大的不利影响。

由此可见, 如果能够在一定程度上克服或者减小这类摩擦, 对于中伊双方都是一件双赢 的事情。

\section{4. 美国对伊斯兰世界政策的改变为 “一带一路” 带来的可能契机}

据上文论述，“9.11”事件过后，美国开始重新考量对伊斯兰国家的相关外交政策，更 倾向于公众外交、联合各国进行各类反恐行动。与此同时, 特朗普上台之后, 美国经历了对 华贸易保护主义升温、缓和的大起大落的阶段, 使得中国在国际经济贸易中的地位反而有所 上升，甚至有一些声音说 “未来将会有中美双轨并行的贸易体系”。

但是, 由于从目前来说, 美国仍然是世界上唯一的超级大国, 美国的利益触角早已遍及 包括一带一路辐射范围在内的世界各个角落。所以, 美国如果能够以更加客观的角度审视伊 斯兰世界, 对中国无疑是有好处的。因为如果只是用利益来衡量两国关系, 那么就可以寻找 共同点, 谋求共同利益; 但是如果一味以宗教、文明、政治来衡量, 这对中国这样一个多元 文明的非宗教国家来说, 反而还不太容易挖掘其中的平衡点。

\section{1 美国对极端恐怖主义的打击将有利于贸易领域的扩展和深入。}

美国将重心放在反对恐怖主义入侵的同时, 再秉承其 “借力打力” 的传统方法, 必将会 扶植周边政权崛起以对抗极端主义的政治伊斯兰。因此, 我国作为反恐阵营中的一员, 也必 将在此获利。最大的体现就是沿线贸易安全得以保障, 贸易领域也可以由单纯的商品买卖、 基础设施建设等扩展到跨国投资、文化产品等各个领域。

\section{2 美国以利益为导向的外交政策也能促进民众认识的客观化和科学化。}

在将极端恐怖主义势力与一般伊斯兰教徒或政权区分开来后, 也能使我国民众对穆斯林、 对伊斯兰世界有着更为清晰地认识。并且由于信息社会的日趋发达，民众在国内不止能够接 受到国内发布的讯息, 同样也能接受到国外的。当世界对政治伊斯兰有着更为清晰客观的认 识之后，国内的與论环境也会有所改变，有利于维护社会稳定。

\section{3 有利于宗教矛盾的缓和。}

中国要发展 “一带一路”战略, 就不可避免地同伊斯兰国家合作, 这必然会带来一系列 宗教争端。美国的对伊斯兰态度的改变, 由于美国是世界上唯一的超级大国, “美国态度” 在很大程度上影响着 “世界态度” ，使得越来越多的正常穆斯林及其政权意识到文明的冲突 
有时可以为国家的利益让步，这有利于我国在伊斯兰国家宗教矛盾的缓和，且本来我国的自 由的宗教政策就相对美国更有优势，我国对正常、友好穆斯林的态度也更为缓和，美国的 “墨 西哥墙”事件反而使其在穆斯林中的形象有所下降。相比之下更为我国提供了机遇。

\section{References}

[1] Ding Long, An analysis of the relationship between the United States and Political Islam, International Politics Quarterly, vol.03, pp. 69-86, 2013.

[2] J. L. Esposito and V. R. Nasr, Rethinking U.S.Foreign Policy\&Islam after Kosovo, West Asia and Africa, vol.06, pp. 51-55, 1986.

[3] Ma Liangcheng, Study on the relationship between Chinese strategy of opening up to the West and the Islamic world, Master's Thesis of Yunnan University, 2015.

[4] Tian Wenlin, The rise of the "Islamic State"and US'Middle Eastern strategy, Contemporary International Relations, vol. 10, pp. 24-30, 2014.

[5] Zhang Zhizhou, Religious Nucleoli in the Clash of Civilizations between the U.S.A. and the Islamic World as Reflected in the September 11 incident, International Forum, vol. 07, pp. 7-11, 2005 . 